\title{
EXILIOS Y RETORNOS CHILENOS
}

Loreto Rebolledo González 


\section{LORETO REBOLLEDO GONZÁLEZ}

Periodista y antropóloga. Doctora en Historia. Profesora titular Universidad de Chile. 


\section{EXILIOS Y RETORNOS CHILENOS}

Los desplazamientos de población suelen ir acompañados de fuertes cargas emocionales y expectativas cuyo tono será más o menos positivo, según sea el contexto en el cual se dan. En algunos casos, cuando se migra buscando oportunidades de desarrollo individual o familiar, se apuesta por un futuro mejor en el país de llegada y por tanto hay una mirada esperanzadora sobre la vida que se tendrá allí, de forma que los pies se sitúan firmes sobre la tierra; en otros, cuando grupos de personas son desplazadas por situaciones de catástrofe o guerra que les impiden seguir en su terruño, o cuando huyen de persecuciones políticas transformándose en exiliados, la desesperanza, el miedo y la angustia son parte del equipaje con que se desplazan, y así estas migraciones forzadas se viven como un tiempo congelado, un período transitorio de la vida a la espera del regreso. En el último tercio del siglo XX miles de chilenos vivieron el segundo tipo de experiencias.

Hasta avanzado el siglo XX Chile no se caracterizó por ser un país con grandes desplazamientos de población. No atrajo migrantes en cantidades considerables ni tampoco expulsó grandes cantidades de chilenos más allá de sus fronteras, lo que contribuyó a alimentar el mito de nuestra homogeneidad interna. Eso hasta la década del 70, en que el golpe de Estado lanzó a miles de hombres y mujeres al exilio, haciendo evidentes nuestras diferencias así como la incapacidad de resolverlas.

Entre las razones que explican los bajos desplazamientos de población hacia y desde Chile están su ubicación geográfica, en que el desierto por el norte, los hielos antárticos por el extremos sur y el océano pacífico y la cordillera fueron barreras naturales que protegían tanto como aislaban al país del resto del mundo. Por otra parte, las políticas gubernamentales para atraer inmigrantes fueron erráticas, y si bien en algún momento propiciaron la inmigración, no fueron particularmente estimulantes ${ }^{1}$.

Así, en el siglo XIX se decide colonizar la zona de Valdivia y se solicita a Vicente Pérez Rosales captar migrantes extranjeros. En 1869 ya existían 1.365 inmigrantes alemanes, muchos de ellos artesanos y agricultores que colonizaron la región que va entre las actuales ciudades de Valdivia y Puerto Montt (Pérez Rosales 1976, pág. 421). Posteriormente, franceses, suizos, belgas, ingleses, españoles e italianos reclutados por el Gobierno "colonizan" las zonas aledañas a Temuco y se establecen en diferentes a ciudades del Valle Central (Vial, 1981; Pérez Rosales, 1976).

1. En 1885, la proporción de extranjeros en Chile era solo del 2,9\%. En 1907 se detecta un leve incremento, alcanzando los extranjeros un 4,5\%. De ellos, una parte importante eran peruanos y bolivianos vinculados al trabajo de la minería en las salitreras del norte del país. Al analizar períodos largos se constata la existencia de ciertos ciclos en que la inmigración ha sido más visible, los que coinciden con períodos de crisis económica o períodos de postguerra en Europa y con persecuciones políticas en países latinoamericanos, así como con políticas gubernamentales orientadas a atraer artesanos, técnicos y profesionales europeos. 
El interés oficial por la inmigración disminuyó desde 1890. "Apareció la xenofobia (la cual se hizo muy aguda, por algunos años al empezar el siglo XX); se polemizó sin tregua ni fin si era mejor traer católicos (decían los clericales) o protestantes (afirmaban los laicos); se enfatizó el peligro que significaban las minorías extranjeras cuando no se fusionaban con los chilenos" (Vial, 1981, pág. 722).

A partir de 1938, en el contexto de la Segunda Guerra Mundial y ante la persecución de judíos en Europa por gestiones de Alto Comisionado para los refugiados de Alemania, llegan 300 familias, a las que posteriormente se agregaron otras. Además, llegaron otros europeos, entre ellos republicanos españoles que habían llegado por diferentes medios, y otros en el Winnipeg.

A comienzos del siglo XX habían arribado a Chile inmigrantes sirios, palestinos y libaneses. Se estima que hasta 1940 se encontraban entre 8 mil a 10 mil inmigrantes de origen árabe (Olguín y Peña, 1990)². A estas inmigraciones transoceánicas hay que agregar un flujo pequeño, pero relativamente constante, de latinoamericanos que a lo largo del siglo XX encontraron en Chile un lugar de exilio luego de tener problemas políticos en sus respectivos países.

Si bien Chile no ha sido un gran receptor de población, tampoco fue un gran expulsor de esta en el pasado, siendo los emigrantes más importantes, en términos numéricos y de fama, los buscadores de oro en California, las prostitutas que se instalaron en los puertos del Pacífico, los mapuche y sureños que marcharon hacia la Argentina, los chilotes que trabajaban por largas temporadas en la Patagonia argentina.

Más allá de las migraciones económicas y antes de 1973, también hubo exilios por razones de carácter político. Entre otros, destacan el destierro de O’Higgins en los inicios de la República; más tarde, Arturo Alessandri Palma y Carlos Ibáñez del Campo, que debieron salir del país junto a algunos de sus seguidores; la persecución desatada por el Gobierno de González Videla contra los comunistas en los 50 obligó a varios de ellos a salir exiliados, entre ellos Pablo Neruda. Sin embargo, estos exilios no afectaron a contingentes amplios de personas y su duración en el tiempo fue relativamente breve.

Jamás en la historia de Chile se había registrado una salida forzada de chilenos tan masiva en tan corto plazo y hacia lugares tan diversos como la iniciada a partir de septiembre de 1973. Miles de hombres y mujeres chilenos salieron del país como resultado de la persecución política y la represión desatada por el Gobierno dictatorial, y esos flujos de personas se vieron incrementados en diferentes momentos, de acuerdo a los ciclos represivos.

\section{VIVIR LEJOS DE LA PATRIA}

El Gobierno militar utilizó diversos mecanismos para expulsar del país o para impedir el reingreso a Chile a los opositores a su Gobierno. A las primeras disposiciones difundidas a través de bandos en los días inmediatamente posteriores al golpe, se agregó

2. Hasta la actualidad, Chile cuenta con la colonia palestina más importante del mundo. 
más adelante un conjunto de disposiciones que se transformaron en el marco "legal" para justificar el exilio. En esta perspectiva es que se dictaron una serie de decretos ley que fundamentaron jurídicamente la prohibición de vivir en Chile; a esto se agregó el Programa de Liberación de Detenidos Políticos, eufemismo usado para dar cuenta de la deportación de compatriotas a través de la expulsión o la condena al extrañamiento.

Establecer el número exacto de exiliados chilenos es una tarea inútil; las cifras son inciertas y contradictorias por razones de diverso orden. Por el deseo de las autoridades de la época de minimizar el problema, la información oficial es poco fiable; por otra parte, porque en muchos casos quienes salieron del país buscaron no dejar registro de su salida a la espera del reingreso posterior. A ello hay que agregar que quienes abogaban por el retorno de los exiliados consideraban que, siendo mayor la magnitud de personas involucradas, se ejercería una mayor presión sobre las autoridades. Por ello se hablaba de un millón de chilenos exiliados.

Sin embargo, las estimaciones más coincidentes dan cuenta de 400.000 chilenos y chilenas que debieron abandonar el país por razones políticas (Bolzman, 1993). Esta cifra coincide con la calculada por la historiadora Carmen Norambuena: "Según los antecedentes y la documentación que poseemos habrían salido del país 408.000 personas, siendo sus principales destinos Argentina $(50,785)$, Estados Unidos $(7.87 \%)$, Venezuela (6.18\%), Canadá (3.85\%), Francia (3.68\%) Italia (2.38\%), Suecia (2, 38\%) y Australia (2,21\%)" (Norambuena: 2000, pág. 178). No obstante, esta cifra duplica la entregada por otros organismos. Por ejemplo, en 1990 la Oficina Nacional de Retorno (ONR), el Servicio Universitario Mundial y el Comité Intergubernamental para los Migraciones CIM (Vaccaro, 1990) calculaban que los exiliados políticos representaban alrededor de 200 mil personas dispersas entre los cinco continentes y en una diversidad amplia de países. De esto da cuenta la existencia de suscriptores en 60 países de la Revista Chile América, que circulaba entre exiliados políticos (Ibíd). Esta cifra del exilio político es cercana a la que da la Vicaría de la Solidaridad, que calcula que alrededor de 260.000 personas habían sido obligadas a vivir fuera del país por razones políticas.

La dificultad de establecer las cifras del exilio es casi un lugar común entre diversos autores que se han abocado a la investigación sobre este tópico. "En principio los exiliados han huido, llegan sin pasaporte y deben acogerse al estatuto legal de refugiados. Pero ya entre las primeras oleadas de exiliados se pudo constatar que aquellos que habían logrado partir con su pasaporte hacían todo lo posible por conservarlo. Aferrarse al pasaporte respondía a un deseo muy profundo: marcar, aunque sólo fuera con un documento, la voluntad de retorno. Esta actitud ha traído como corolario una dificultad enorme para apreciar el tamaño de la comunidad exiliada, porque junto a aquellos que tienen el documento administrativo oficial, hay una enorme cantidad de exiliados de facto que sobreviven con papeles provisorios, permiso de estudiante, pasaporte de turista e incluso una doble nacionalidad" (Vásquez y Araujo, 1990, pág. 27).

Esta dificultad en dimensionar el número de inmigrantes no es excepcional al exilio. También se constata en las migraciones de carácter económico, en los desplazados de guerra, donde la cifra de indocumentados suele ser imposible de calcular y algunas 
de las estrategias de ingreso al país suelen ser similares a las mencionadas en el párrafo anterior.

A las dificultades señaladas para establecer las cifras reales del exilio, hay que agregar la fuerte emigración de carácter económico que se produjo por efecto de las políticas de ajuste introducidas por el Gobierno, que dispararon la inflación y la cesantía en Chile a comienzos de la década del 80. La emigración económica es difícil de precisar en números. Además, es casi indistinguible del exilio político, pues estos migrantes tendieron a sumarse a las actividades y a vivir en los mismos barrios donde solían congregarse los exiliados ${ }^{3}$.

El exilio chileno abarcó a personas con y sin militancia de un vasto espectro político y ha sido caracterizado como un exilio familiar, lo cual es respaldado por las cifras de reunificación familiar y por diversas investigaciones. Por ejemplo, Norambuena (2000) estima que "el 76,15\% de los titulares de exilio fueron acompañados por sus respectivas familias, siendo la mayoría de ellos casados. El 79,35\% tenían familia integrada por dos, tres y cuatro personas. También se puede caracterizar como un proceso de sello masculino pues el $66.82 \%$ de los titulares eran varones. Sin embargo la presencia de un 33.18\% de mujeres, señaladas como causantes del abandono del país, merece una especial consideración en relación al grado de compromiso que estas tenían con el derrocado régimen. Los hombres y mujeres comprendieron que si su grupo inmediato seguía en el país, se vería expuesto a represalias de diverso tipo. De otra parte, frente a la amenaza externa el grupo nuclear se cohesionó tomando la decisión, cuando se pudo, de no separarse, de partir o de reunirse en el extranjero" (Norambuena, 2000, pág. 178.)

Aun cuando había exiliados de diferentes edades, el grueso de ellos tenía un promedio de 35 años de edad, lo cual es coincidente con la juventud de los detenidos desaparecidos, fusilados y muchos de los prisioneros políticos, de los cuales hay registros más fidedignos. Los que no salieron casados, dada su juventud, en el exilio tendieron a formar parejas y a tener hijos que nacieron en el país de acogida y pasaron su infancia allí sin conocer ni haber vivido jamás en Chile.

La cantidad de hijos en general fue pequeña dada la precariedad de la vida en el exilio y el proyecto de retorno a Chile del grueso de los exiliados, por otra parte un porcentaje importante de las parejas que salieron juntas en el exilio se separaron por la presión que significó tener que adaptarse a nuevas sociedades y a situaciones estresantes propias de su condición de exiliados. Esto explica la gran cantidad de mujeres jefas de hogar que había entre los exiliados, lo que se confirmó al retorno, de acuerdo a los datos de la ONR (Oficina Nacional de Retorno). Las familias eran pequeñas, con no más de tres integrantes, y entre los hogares de exiliados un $51,8 \%$ tenían jefatura de sexo masculino y $48,2 \%$ del femenino, El alto porcentaje de jefatura de hogar femenina da cuenta del

3. Muchos exiliados económicos que se ubicaron en países de América Latina solo se incorporaron a los grupos de exiliados cuando habían tenido una militancia política anterior. En el caso de los países europeos, a veces el exilio económico se enmascaró bajo la fórmula de reunificación familiar, y ello hizo más indistinguible a los exiliados políticos de los migrantes económicos. 
proceso de desestructuración familiar que se produjo en el exilio, donde muchas parejas se separaron y las madres quedaron a cargo de los hijos.

El exilio chileno estaba conformado por una gran cantidad de profesionales y estudiantes universitarios, a los que se agregaban, aunque en menor proporción, obreros, campesinos y técnicos y un número considerable de artistas e intelectuales, entre los que destacaban escritores, pintores, músicos y actores. El predominio de profesionales y técnicos también es destacado por la ONR, que estableció que un 50.81\% de los retornados estaba en esta categoría y un $19,15 \%$ se ubicaba como obreros o trabajadores asimilados ${ }^{4}$. Es interesante resaltar que 1.300 de esos profesionales se habían formado en el exterior sin costo alguno para el Estado Chileno. Dentro de los profesionales existía un grupo importante de académicos que habían salido del país al ser intervenidas las Universidades después del golpe de Estado, los cuales se ubicaban en distintas Universidades latinoamericanas ${ }^{5}$ y de otros países $^{6}$.

Si bien no se han medido los efectos del exilio desde esta óptica, pues se tiende a ver los efectos y aportes de los migrantes en las sociedades de acogida, no deja de ser interesante considerar qué ocurre cuando un país tiene viviendo fuera de sus fronteras y sin posibilidad de regresar un contingente considerable de población joven, académicos, intelectuales y artistas, así como estudiantes, profesionales y técnicos.

\section{DE DULCE Y AGRAZ}

El exilio chileno fue bien recibido por los países adonde llegaron los exiliados gracias a la simpatía que había generado el proyecto de la Unidad Popular, el respeto por la muerte de Allende y el amplio repudio que generó la violencia con la que se impuso Pinochet y la Junta Militar. Así, Le Monde describió el golpe militar como: "La tragedia de un hombre, la tragedia de una nación, de una revolución a través de la ley, o de un socialismo dentro de la ley; una tragedia con implicaciones mundiales", lo que preparó el terreno para la llegada y acogida solidaria a los seguidores del Gobierno derrotado que salieron al exilio.

No obstante, la buena acogida logró mitigar solo en parte la llegada e instalación de los exiliados chilenos en los 60 países -o más- por los cuales se dispersaron. Los problemas psicológicos y de salud mental que suelen acompañar a los refugiados y exiliados no fueron ajenos a los chilenos. A la sensación de derrota y despojo se agregaron los

4. Entre esos profesionales destacaban 130 médico-cirujanos, 135 ingenieros civiles, agrónomos y de minas, 51 arquitectos y 40 cirujanos-dentistas (Informe anual ONR, 1993).

5. El Consejo Latinoamericano de Ciencias Sociales, CLACSO, con sede en Argentina, tuvo un papel fundamental en distribuir en diversas universidades de Latinoamérica a los académicos chilenos.

6. Desde 1974 la política inmigratoria de Venezuela fue selectiva. Un flujo de técnicos y profesionales de Chile, Uruguay y Argentina se radicaron en Caracas huyendo de las dictaduras en sus países y otros atraídos por el boom petrolero. Por su parte, el exilio latinoamericano en México siguió cauces similares, repitiendo el modelo del exilio republicano español que atrajo a intelectuales y artistas. 
efectos de la tortura y la prisión en quienes fueron expulsados o condenados a la extradición y que se manifestaron en la forma de depresiones y angustia.

El conjunto de hombres y mujeres, más allá de las formas en que llegaron al exilio, compartieron el sentimiento de desarraigo, de sentir que sus vidas habían quedado escindidas, una parte en Chile -país al que se esperaba volver lo más pronto posible-y la otra en el país de llegada, al que se veía como un lugar de paso. Esta sensación de transitoriedad dificultó, especialmente en los primeros tiempos, asumir la nueva realidad y adaptarse a la nueva situación, y generó problemas en los niños, para quienes su vida era la que transcurría en el país en que vivían y en muchos casos en donde habían nacido, por lo cual no les resultaba fácil entender la insistencia de sus padres en tratar de socializarlos en la cultura chilena, a la vez que en las escuelas se buscaba su integración a la cultura del país donde se encontraban.

A estos problemas hay que añadir las dificultades materiales que implica tener que "armarse" una vida en otro lugar, sin redes familiares de apoyo, sin trabajo ni reconocimiento de títulos y experticias técnicas o de estudios, sin conocer la lengua del país al que llegaron muchos chilenos; sin ropa adecuada para climas más fríos y sin una vivienda. Si bien los que llegaron asilados, refugiados o expulsados tuvieron el apoyo de los organismos de derechos humanos de Naciones Unidas o de los países que los acogieron, fueron muchos los que tuvieron que resolver estos problemas materiales y cotidianos a partir de propio su esfuerzo y gracias al apoyo y la solidaridad de grupos políticos afines, agrupaciones de estudiantes, sindicatos o grupos de iglesia. No obstante la precariedad laboral, caracterizó a la primera etapa de la mayor parte de los exiliados los reconocimientos de títulos o estudios -cuando los había-, que demoraron y donde no siempre fue posible la homologación, por lo cual muchos debieron realizar trabajos de aseo y limpieza o realizar otras actividades ajenas a su formación y para las cuales estaban sobrecalificados.

El exilio implicó una serie de cambios de todo tipo en la vida y en los cotidianos de los exiliados: el paso del hemisferio sur al norte; vivir en el trópico o en la nieve sin estaciones intermedias, o bien con las estaciones invertidas; la dislocación de las horas de luz, sin demasiada distinción entre el día y la noche; llegar desde una sociedad subdesarrollada a una desarrollada, o bien, el paso a países socialistas o más pobres del tercer mundo.

Todo ello, de por sí, trastocó el mundo de los exiliados. Sin embargo, el cambio más fuerte, y que los interpeló de manera más frontal en su identidad, fue el de las diferencias culturales, frente a las cuales existió la opción de defenderse enclaustrándose en su cultura o abriéndose a las nuevas ideas, comportamientos y formas de ser que se les presentaban.

En el exilio, frente a la derrota y la inseguridad que representaba el vivir fuera de Chile; al quiebre de los proyectos políticos y de vida, los exiliados construyeron en un comienzo una nueva identidad, donde lo central era la política. La política era la razón de su extrañamiento, lo que le daba un sentido a su presente en otro país, haciéndoles sentir que, pese a los fracasos recientes, esa parte de su identidad era valorizada por los otros y era también un proyecto de futuro, ya que las transformaciones políticas serian las que les permitirían volver. 
Como el retorno fue para los exiliados el proyecto de vida desde que salieron, como lo es para todo aquel que es forzado a vivir fuera de su patria, desde el comienzo se empeñaron en no perder su cultura y trasmitirla a sus hijos, así como introducirlos en la historia pasada y reciente de Chile. En la preservación de la cultura a nivel cotidiano la familia jugó un papel central: tanto la familia nuclear como la familia "sustituta", donde los amigos y compañeros exiliados suplieron los roles de la familia extensa ausente. Todos ellos trasmitieron un imaginario de Chile a los niños, a través de relatos y anécdotas, mientras las madres reforzaron el vínculo con la familia que quedó en el país, a través del envío de cartas, fotos y cassettes. En otros casos, cuando la amenaza de aculturación era más fuerte por la eventual pérdida de la lengua materna o por la cantidad de horas que los niños pasaban fuera de sus hogares, se crearon "escuelas" en las que se les enseñaba Castellano e Historia.

La articulación entre cultura y política fue el modo de preservar el vínculo con Chile y el testimonio cotidiano con la lucha y resistencia contra la dictadura, pero además fue la forma de hacer explícita una identidad propia frente a las otras comunidades de exiliados y los habitantes del país de recepción. Ello se vio facilitado por la amplitud del exilio, que incluyó a numerosos intelectuales y artistas, y también por la capacidad organizativa que los exiliados llevaron en sus maletas y que habían aprendido en su práctica política en Chile. Clubes deportivos, radios, periódicos, revistas, agrupaciones musicales, talleres de teatro, además de los propios partidos políticos, fueron creados rápidamente por los exiliados, no solo con el sentido de ayudarse y reforzar una identidad, sino para denunciar lo que ocurría en Chile y crear una actitud de rechazo hacia la dictadura de Pinochet

Más allá de la buena voluntad de los gobiernos, en algunos de esos países de acogida no existía experiencia previa en la recepción de refugiados políticos, lo que implicó que las políticas de integración cultural fueran más cercanas a las expectativas que se tiene respecto a los inmigrantes, que a los que se perciben como huéspedes transitorios. Las políticas gubernamentales de la época se movieron entre dos polos: la integración de los exiliados al país de acogida o la tolerancia y fomento al pluralismo cultural. Los efectos de ambos tipos de políticas tuvieron efectos diferentes entre quienes optaron por retornar a Chile y los que decidieron quedarse como inmigrantes.

En algunos países se fomentó, a través de financiamientos específicos, la organización de instituciones de chilenos con fines culturales y deportivos que les permitieran recrear sus identidades ${ }^{7}$. En Canadá, y Suecia, por ejemplo, múltiples radios, revistas, organizaciones deportivas y musicales de chilenos, recibieron apoyo financiero de instituciones de los gobiernos. Incluso se facilitó el aprendizaje del castellano a los niños, para que no perdieran la lengua materna. Hubo en estos casos una voluntad explícita

7. No todos los gobiernos tuvieron una política que buscaba preservar la diversidad cultural. En otros casos, como el del gobierno danés, la actitud fue la de la integración a la sociedad de los exiliados, tratándoles más como inmigrantes, que como gente que estaba transitoriamente allí, por ello el esfuerzo era para que aprendieran bien el idioma y que se adaptaran rápidamente. 
de los gobiernos de fomentar la diversidad cultural y un funcionamiento relativamente autónomo en términos culturales de las organizaciones de exiliados y migrantes.

Esta política, correcta y positiva para los exiliados que retornaron, parece haber tenido resultados más discutibles entre quienes decidieron hacer el tránsito de exiliado a inmigrante. Al permitir la autoreproducción de las comunidades de extranjeros y el refuerzo de sus identidades, se facilitó la socialización de los hijos en la cultura de sus padres, lo cual fue una ventaja en el momento del retorno. Sin embargo, colateralmente se retrasó y debilitó el proceso de integración y de adaptación al país de recepción, facilitando las conductas de ghetto, que se expresaron en la coexistencia de múltiples grupos que cohabitaron pero no se enriquecieron mutuamente. Si a ello se suma la segregación barrial y escolar, que auspiciaron algunas políticas de bienestar social, se constata que se crearon las condiciones para la exclusión social de aquellos que decidieron quedarse en el país de acogida como inmigrantes. La ghetización de grupos de chilenos favoreció la discriminación, situación que se hizo visible cuando cambiaron las condiciones políticas y económicas de algunos países, como ocurrió en Suecia a fines de los 80, donde ciertos chilenos fueron percibidos como delincuentes.

La actitud abierta y de apoyo a los refugiados que tuvieron algunos países europeos permitió que amplios grupos de chilenos con pocas posibilidades de movilidad y desarrollo social en Chile se transformaran en inmigrantes. A través del proceso de reunificación familiar, integrantes de sectores populares y medios, muchos de cuyos integrantes no tenían vínculos directos con la política pero habían sido afectados por la persecución a familiares cercanos, se trasladaron a esos países, y dadas las comodidades y facilidades recibidas en términos económicos, de capacitación, seguridad social, y sobre todo la posibilidad de educación para los hijos, decidieron instalarse allí. De modo que al terminarse el exilio se quedaron como inmigrantes.

En América Latina, más que los gobiernos -exceptuando a México y Venezuela- fueron las sociedades de esos países las que acogieron a los exiliados y las que crearon las condiciones para su instalación y reproducción. En aquellos países en que los exiliados chilenos recibieron facilidades para su instalación y donde tuvieron las mismas posibilidades laborales y económicas que los nacionales -en México por ejemplo-, se dio que muchos exiliados que vivían en estos países no regresaran a Chile.

Si bien el exilio es una vivencia difícil para todos, hubo ciertas particularidades, dadas por la edad, que es importante considerar. Para los adultos mayores, con una vida hecha, fue más difícil adaptarse a una nueva sociedad. Si bien corrieron menos riesgos de anomia y desestructuración que los más jóvenes, sus estructuras de personalidad más rígidas, sus modos de hacer y de ser eran más difíciles de cambiar, lo que dificultó su adaptación. En relación a ello, las comunidades de exiliados jugaron un papel central en acogerlos y otorgarles el rol de abuelos. Los exiliados más jóvenes mostraron mayor capacidad de adaptación social y cultural, sin embargo también estuvieron más propensos a la depresión y la anomia, especialmente en el primer período del exilio.

En el caso de los niños mayores y adolescentes, la situación también fue compleja, pues fueron arrancados de la "tierra feliz de la infancia" para vivir en culturas diferentes; asimismo, años más tarde, debieron enfrentar el mismo proceso al retorno de sus padres, 
después de haber hecho el esfuerzo de adaptación y integración en el país de acogida. Ellos debieron vivir la tensión de una doble y simultánea exigencia: la adaptación cultural y social para rendir en la escuela y no perder las raíces, hablar la lengua del país de origen y conservar sus costumbres, que en muchos casos eran abiertamente diferentes a las del país de acogida. Esta tensión hizo crisis cuando se comenzó a cerrar el ciclo del exilio y se planteó el tema del retorno. A partir de 1984, ante la presión internacional y el accionar de diversos organismos chilenos de derechos humanos, comienzan a salir las primeras listas con los nombres de exiliados a los que se les permitía reingresar a Chile. Comienza poco a poco el proceso de retorno.

El drama del exilio de los padres, con todas las pérdidas que conlleva una situación como esta, se convirtió en el fantasma y en la realidad de muchos niños y adolescentes hijos de exiliados chilenos. En la novela de José Donoso, El jardín de al lado, un joven a quienes sus padres quieren hacer retornar a Chile dice: "Lo que más le indignaba, declaró, era que sus padres lo tomaran a él como pretexto para volver a Chile, asegurando que deseaban volver porque no querían que perdiera sus raíces, que se desinteresara... por las cosas chilenas, que no se reconociera en el idioma, en su familia, en las tradiciones... Mis raíces están en París, hace siete años que salí de Chile... He crecido e ido al colegio en Francia, con compañeros franceses, viviendo como viven los franceses de mi edad...".

Las mujeres vivieron el exilio de distinta manera que los hombres: mientras estos, en una primera etapa, se dedicaron a la militancia y las labores de solidaridad, ellas debieron actualizar su sentido de realidad y crear las condiciones para la instalación en el nuevo país, tensionadas por el mandato de género de trasmitir a los hijos su cultura y a la vez de facilitarles la adaptación a la nueva sociedad. Por otra parte, la interacción con otros modos de ser mujer y la práctica de independencia y autonomía que debieron desplegar, especialmente al tener que hacerse cargo de la jefatura de sus hogares cuando se produjeron separaciones, provocaron cambios en sus identidades de género, donde tomó importancia la dimensión laboral y política en un sentido más amplio que el partidario; en fin, cambios que se confrontaron al retorno.

Para los exiliados de origen mapuche el exilio también abrió oportunidades en lo referente a educación de los hijos, capacitaciones laborales, y fundamentalmente les mostró cómo en otros países la diversidad cultural no era un discurso, sino una práctica fomentada por el Estado a través del financiamiento de organizaciones de carácter étnico. Esto contribuyó a la toma de conciencia sobre una identidad étnica, que hasta entonces había estado encubierta bajo el discurso clasista de la izquierda.

La vivencia del exilio fue un hito fundamental en las vidas de quienes lo vivieron, que marcó un quiebre biográfico. Así lo demuestran las memorias individuales y colectivas del exilio y el retorno. Sin embargo, ese quiebre también permitió abrir fronteras geográficas y mentales que posibilitaron sentirse formando parte de un mundo mucho más amplio y menos ajeno, cuando esa posibilidad, abierta por la globalización, aún no se presentaba.

Una ganancia del exilio fue permitir que un grupo importante de chilenos se abriera hacia el mundo y enriqueciera sus perspectivas en el contacto con otras realidades y 
culturas. La cantidad de intelectuales, políticos, profesionales, obreros y estudiantes que salieron fuera de un país pequeño como Chile, caracterizado por la insularidad, tuvo efectos importantes en términos individuales y colectivos en la cultura, en la política y en términos intelectuales.

El exilio y el trabajo de los centros de estudios privados que surgieron después de 1973 en Chile permitieron una circulación internacional de los intelectuales, desconocida hasta la fecha. Santiago había sido un centro de discusión latinoamericana hasta 1973, época en que se trasladó a México. Después del golpe, y gracias a la iniciativa de CLACSO, se crearon grupos de trabajo regionales, configurándose una especie de Universidad itinerante que remplazó así a las universidades intervenidas, afirma Lechner. Todo ello contribuyó "a disminuir el provincialismo (frecuentemente acompañado de "europeísmo" acrítico) y facilitó la renovación de un pensamiento relativamente autónomo de las estructuras partidistas en cada país. Adquiriendo mayor autonomía respecto a las organizaciones políticas, la discusión intelectual (sobre todo en las izquierdas) logra desarrollar un enfoque más universal (menos instrumental) de la política" (Lechner, 1990, pág. 34).

El retorno fue una nueva migración, en este caso voluntaria, con efectos más o menos devastadores a nivel personal, en relación a la capacidad de integración y adaptación logrados en los países de recepción. Por otra parte, al retorno se constata que volver no era un proyecto de vida, aunque así se lo sintió y vivió en el exilio, lo que dificultó unir los hilos del pasado y del presente, de "allá" y "acá". Retornar fue volver a vivir la nostalgia, esta vez, del país de acogida.

Pero también fue vivir muchas de las dificultades que se vivieron en la primera etapa del exilio. La reinserción laboral de los retornados, la homologación de estudios y títulos, la pérdida de los derechos previsionales acumulados en los países donde se vivió, se sumaron al desencuentro con un país del cual se había estado físicamente ausente, pero mentalmente presente durante más de una década y media.

Así como la década del 70 marcó el inicio de la masiva salida de chilenos rumbo al exilio, la década de los 90 fue testigo del retorno de esos exiliados y su instalación en el país. Los 90 fueron además los años en que comenzaron a llegar a Chile inmigrantes provenientes de Perú, algunos, los primeros, en calidad de refugiados, luego otros que llegaron buscando mejores oportunidades laborales. A ellos se han ido agregando bolivianos, ecuatorianos, colombianos, y en el último tiempo haitianos.

Los exilios de los 70, compartidos por chilenos, argentinos y uruguayos, se dio en un momento en que todavía estaban vigentes las grandes utopías, lo cual contribuyó a que los exiliados latinoamericanos del Cono Sur contaran con la simpatía y generosidad de los países europeos, que los acogieron y les dieron refugio. Situación muy diferente a la vivida en los años posteriores a los 90, donde centroamericanos y colombianos, también perseguidos políticos, fueron vistos como inmigrantes indeseables en el marco de políticas migratorias restrictivas.

En los 90 cambió radicalmente la inmigración debido a los fuertes desplazamientos desde Europa del Este y desde África y Asia hacia Europa Central, y modificó también las condiciones de los refugiados. Apareció el racismo, la xenofobia, etc., situaciones 
que no estaban presentes de manera tan frontal en la década anterior y que lamentablemente tampoco son ajenas a Chile.

\section{REFERENCIAS BIBLIOGRÁFICAS}

Bolzman, C., "Exilio, familia y juventud", en Montupil, F. (director), Exilio, derechos humanos y democracia. El exilio chileno en Europa, Coordinación Europea de Comités Pro-retorno, Santiago de Chile, s.e., 1993.

Lechner, N., "De la revolución a la democracia", en Debate feminista, Año I, Vol.1, México, marzo 1990.

Norambuena, C., "Exilio y retorno. Chile. 1973-1994", en Garcés, M., et al. (comps.), Memoria para un nuevo siglo. Chile, miradas a la segunda mitad del siglo XX, Santiago de Chile: LOM Ediciones, 2000.

Olguín, M., Peña, P., La inmigración árabe en Chile, Santiago de Chile: Ediciones Instituto Chileno-Árabe de Cultura, 1990.

Pérez Rosales, V., Recuerdos del pasado, Santiago de Chile: Editora Nacional Gabriela Mistral, 1976.

Oficina Nacional De Retorno, Informe Anual, 1993.

Vázquez, A., Araujo, A. M., La maldición de Ulises. Repercusiones psicológicas del exilio, Santiago de Chile: Editorial Sudamericana, 1990.

Vaccaro, V., "El reencuentro es posible. Seminario exilio-retorno de académicos/ intelectuales", organizado por Oficina Nacional de Retorno, Servicio Universitario Mundial, SUM, Universidad Academia de Humanismo Cristiano, diciembre 1990.

Vial, G., Historia de Chile (1891-1973). La sociedad chilena en el cambio de siglo (1891-1920). Tomo II, Santiago de Chile: Editorial Santillana del Pacífico, 1981. 